\title{
Bacteroides ureolyticus, a New Species to Accommodate Strains Previously Identified as "Bacteroides corrodens, Anaerobic"
}

\author{
FRANCIS L. JACKSON AND YVONNE E. GOODMAN \\ Department of Medical Bacteriology, University of Alberta, Edmonton, Alberta, Canada
}

\begin{abstract}
The name Bacteroides ureolyticus is proposed for a species to accommodate strains of gram-negative, urease-positive, anaerobic, corroding rods previously incorrectly referred to as Bacteroides corrodens. The organisms are catalase negative and reduce nitrate. In peptone-yeast-glucose medium, growth is enhanced by the addition of fumarate and formate, and succinate is the major end product. Conventional carbohydrate fermentation tests are negative. The oxidase test is positive and is markedly inhibited by azide. Absorption bands of reduced cytochromes are seen by visual spectroscopy at $550 \mathrm{~nm}$ (cytochrome $c$ ) and 555-560 nm (b-type cytochrome); no cytochrome $a$ band was detected. Most strains hydrolyze gelatin and casein. Strains with very weak proteolytic activity are also encountered. The cells are nonflagellated but may show "twitching motility." Electron micrographs of five of seven strains reveal polar pili. Strains that lack pili do not produce spreading colonies or show twitching motility. The guanine-plus-cytosine content of the deoxyribonucleic acid is in the range of 28.0 to $30.0 \mathrm{~mol} \%$. Strain NCTC 10941 is designated as the type strain.
\end{abstract}

Eiken (2) applied the name Bacteroides corrodens to certain gram-negative rods that formed "corroding" colonies on agar media and that were considered to be anaerobes. It has since become clear that the Eiken collection contained organisms of several different kinds. Some of the strains, including that later designated by Henriksen as the type strain (4), were found to be facultative anaerobes. Three of Eiken's anaerobic strains were later found by Henrichsen (3) to have polar flagella. Nonflagellated anaerobic strains, corresponding in many respects to Eiken's description of $B$. corrodens, have since been studied in detail by Khairat (8) and by Jackson et al. (7). Organisms of this type are now commonly referred to as $B$. corrodens, and we reported in an earlier publication (6) that these anaerobic strains can be clearly distinguished from the facultative organisms, which we placed in a new genus, Eikenella. The facultatively anaerobic Eikenella organisms have a deoxyribonucleic acid (DNA) guanine-plus-cytosine $(\mathrm{G}+\mathrm{C})$ content of 56 to $58 \mathrm{~mol} \%$ and do not produce urease, whereas the anaerobic strains have a DNA G+C content of 28 to 30 $\mathrm{mol} \%$ and are urease positive. It is our purpose in this paper to refer to some instances of possible confusion in the recent literature on these organisms and to propose a new specific name for the anaerobic, urease-positive organisms that up to now have been called $B$. corrodens.

\section{MATERIALS AND METHODS}

Bacterial strains. Strain NCTC 10941 was originally isolated from amniotic fluid at the Misericordia Hospital, Edmonton, Alberta, Canada, and was referred to us for identification by J. H. Stirrat. Strains UAH 1 (from an infected face lesion) and UAH 2 (from an infected heel) were isolated in our diagnostic service at the University of Alberta Hospital. Strain B 912 was sent to us by S. M. Finegold, Veteran's Administration Center, Los Angeles, Calif., and strain 7814 was obtained from L. V. Holdeman, Virginia Polytechnic Institute and State University, Blacksburg, Va. Strains NC-1 (=NCTC 10948) and NCL-20 (=NCTC 10949) were obtained from the National Collection of Type Cultures, Colindale, London, England.

Methods. Most of the methods used for investigation of the strains included in our study were described in earlier publications $(5-7,9)$. Gas chromatography of end products was performed by the methods described in the Anaerobe Laboratory Manual issued by the Virginia Polytechnic Institute, Blacksburg, Va. The fumarate-formate medium was prepared according to the specifications of Smibert and Holdeman (12). Heavy inoculation of standard Christensen urea agar medium was used for demonstration of urease production by the anaerobic corroding rods.

For the oxidase test, a new method (F. L. Jackson, unpublished data) was used which we have found to be superior to the method of Kovacs. Bacteria from plates were suspended in $0.025 \mathrm{M}$ phosphate buffer (pH 7.0) to an optical density of 0.7 at $600 \mathrm{~nm}$, and 1.2 $\mathrm{ml}$ of this suspension was placed in each of two small tubes $(1.3 \mathrm{by} 10 \mathrm{~cm})$. To one tube, $0.2 \mathrm{ml}$ of a $0.1 \%$ 
solution of sodium azide was added; to the other, 0.2 $\mathrm{ml}$ of phosphate buffer, followed by $0.23 \mathrm{ml}$ of a $1 \%$ solution of dimethylparaphenylenediamine monohydrochloride, was added. The tubes were placed in a rack and shaken at 120 oscillations per min, at an amplitude of 1.5 inches (ca. $3.8 \mathrm{~cm}$ ) for $2 \mathrm{~min}$ at $30^{\circ} \mathrm{C}$. The color change was noted. Azide sensitivity of the oxidase system was demonstrated by failure or marked inhibition of color development in the azide-containing tube. Known positive- and negative-control organisms were tested in parallel with the unknowns.

Absorption bands of reduced cytochromes were observed by visual spectroscopy by the method of Shobe (11).

\section{RESULTS AND DISCUSSION}

The characteristics of the seven strains examined are presented in Table 1. There was close overall similarity between the strains, except for differences in protease activity (casein and gelatin digestion) and possession of polar pili and associated ability to form flat, spreading colonies (Table 1).

Brooks et al. (1) claimed that strain VPI 7814, identified at the Virginia Polytechnic Institute as a strain of $B$. corrodens, has a DNA G+C content of $55.0 \mathrm{~mol} \%$ and shows a high degree of DNA homology with certain Eikenella strains. We examined two samples of this strain, kindly sent to us by L. V. Holdeman, of the Virginia Polytechnic Institute, and were unable to confirm the DNA $\mathrm{G}+\mathrm{C}$ content reported by Brooks et al. (1). The value we obtained in three estimations on the two samples was $28.4 \mathrm{~mol} \%$, which is similar to that found for other anaerobic strains identified as $B$. corrodens. The actual subculture used by Brooks is no longer available, but the organisms we examined are the same as those referred to in the paper by Smibert and Holdeman (12). It is most improbable that organisms differing by $29 \mathrm{~mol} \%$ in DNA G+C

TABLE 1. Characteristics of Bacteroides ureolyticus ${ }^{a} s p$. nov. and its type strain

\begin{tabular}{|c|c|c|c|}
\hline Characteristic & $\begin{array}{l}\text { B. ureolyticus (no. } \\
\text { of strains giving } \\
\text { positive result) }\end{array}$ & $\begin{array}{c}\text { Type strain (NCTC } \\
\text { 10941) }\end{array}$ & $\begin{array}{l}\text { Strains giving the } \\
\text { less common re- } \\
\text { sult }\end{array}$ \\
\hline Gram-negative rods & $+(7 / 7)$ & + & \\
\hline Cell dimensions $(\mu \mathrm{m})$ & $0.5 \times 1.5-4.0^{b}$ & $0.5 \times 1.5-4.0$ & \\
\hline Flagella ............ & $-(0 / 7)$ & - & \\
\hline "Twitching" motility & $\pm(5 / 7)$ & + & B $912, \mathrm{NC}-1$ \\
\hline Polar pilic ${ }^{c} \ldots \ldots \ldots$ & $\pm(5 / 7)$ & + & B $912, \mathrm{NC}-1$ \\
\hline Flat, spreading colonies & $\pm(5 / 7)$ & + & B 912, NC-1 \\
\hline Anaerobic ${ }^{d} \ldots \ldots \ldots$ & $+(7 / 7)$ & + & \\
\hline Growth enhanced by fumarate-formate . . . . . . . & $+(7 / 7)$ & + & \\
\hline Oxidase $\ldots \ldots \ldots \ldots \ldots \ldots$ & $+(7 / 7)$ & + & \\
\hline$\ldots \ldots \ldots \ldots \ldots$ & $-(0 / 7)$ & - & \\
\hline$\ldots \ldots \ldots \ldots \ldots \ldots$ & $+(7 / 7)$ & + & \\
\hline Nitrate reduction & $+(7 / 7)$ & + & \\
\hline Lysine decarboxylase & $-(0 / 7)$ & - & \\
\hline Gelatinase (Frazier). & + or weak $(6 / 7)$ & + & VPI 7814 \\
\hline Casein digestion ${ }^{e} \ldots$ & $\pm(6 / 7)^{f}$ & + & VPI 7814 \\
\hline Starch acid ..... & $-(0 / 7)$ & - & \\
\hline Starch hydrolysis & $-(0 / 7)$ & - & \\
\hline $\mathrm{H}_{2} \mathrm{~S}$ production ${ }^{g}$. & $+(7 / 7)$ & + & \\
\hline Indole production & $-(0 / 7)$ & - & \\
\hline Succinate major end product (PYG-FF medium) & $+(7 / 7)$ & + & \\
\hline $\begin{array}{l}\text { Conventional carbohydrate fermenta- } \\
\text { tions }^{h}\end{array}$ & $-(0 / 7)$ & - & \\
\hline $\begin{array}{l}\text { Cytochrome absorption bands at } \mathbf{5 5 0} \\
\text { and } 555 \text { to } 560 \mathrm{~nm} \ldots \ldots \ldots \ldots \ldots\end{array}$ & $+(7 / 7)$ & + & \\
\hline DNA mol\% $\mathrm{G}+\mathrm{C}^{i} \ldots \ldots \ldots \ldots$ & $28.0-29.7$ & 28.0 & \\
\hline
\end{tabular}

${ }^{a}$ Based on seven strains: B912, NC-1, NCL-20, NCTC 10941, UAH 1, UAH 2, and VPI 7814.

${ }^{b}$ Filaments up to and exceeding $20 \mu \mathrm{m}$ in length may occur.

c The ability to move by "twitching" and to form spreading colonies is related to the possession of polar pili.

${ }^{d}$ When grown on cystine hemin agar, tolerates $1 \%$ but not $5 \%$ oxygen.

${ }^{e}$ Demonstrated by growth on casein-cystine-hemin-agar plates (7) in 3 to 5 days.

${ }^{f}$ Strain NCL-20 produces a weak reaction.

${ }^{g}$ Demonstrated by lead acetate paper strip test in 2 days when organisms were grown on cystine hemin or blood agar.

${ }^{h}$ See text for substrates tested.

${ }^{i} T_{m}$ method (7). 
content could show the degree of DNA homology with Eikenella strains quoted by Brooks et al. (1), and it seems likely that some confusion of strains may have occurred in their study.

Smibert and Holdeman (12) reported that they were able to detect flagella on some cells in smears of VPI 7814 stained by flagella stains but that they were unable to detect motility. Electron micrographs taken in our department by $\mathrm{S}$. Shahrabadi have revealed no flagella in subcultures of this organism, but, as is usual with the anaerobic pitting strains, large numbers of long, polar pili were observed. These pili are sometimes formed into bundles, and we have found that the bundles may give an appearance superficially resembling flagella in stained smears observed by light microscopy. Strains that have polar pili are able to form spreading colonies on solid media and show "twitching" motility (3). Strains that lack polar pili, e.g., B 912 (7), do not form spreading colonies and do not show twitching motility.

Robinson and James (10) reported serological similarities between $E$. corrodens and an anaerobic strain (NCL-20 = NCTC 10949) considered to be a member of $B$. corrodens. The anaerobic strain studied by Robinson and James was obtained by us from the National Collection of Type Cultures, London, England, and was found to have a DNA G+C content of $29.2 \mathrm{~mol} \%$ and to produce urease. Any sharing of antigens between NCTC 10949 and Eikenella strains cannot, therefore, be regarded as an indication of close overall relationship between the anaerobes and $E$. corrodens, as the widely different $\mathrm{G}+\mathrm{C}$ contents indicate great genotypic differences. Sharing of antigens between otherwise unrelated organisms is not uncommon, and the Robinson observation does not in itself justify the designation of NCL-20 as a "link" strain between $E$. corrodens and the anaerobic organisms.

Certain anaerobic vibrio-like organisms form "corroding" colonies on agar media, and strains of this kind have been confused with the socalled anaerobic $B$. corrodens and with $E$. corrodens. Two strains we examined had DNA $\mathrm{G}+\mathrm{C}$ contents of 43.0 and $44.7 \mathrm{~mol} \%$. Electron microscopy is valuable for the recognition of the mode of flagellation of these strains, as in some cultures the cells may be mostly nonmotile. Some organisms of this kind may conform to the description of Vibrio succinogenes (12). We refer to them here because, on the basis of conventional sets of tests commonly used for the identification of $E$. corrodens and $B$. corrodens, confusion may easily occur. The production of urease by the anaerobic strains at present called $B$. corrodens is a characteristic that is valuable for differentiating these organisms from $E$. corrodens and from corroding "vibrios." The strains examined by Khairat (8) were described as urease negative, but, as we have previously pointed out (7), this might have been due to the use of a relatively insensitive testing method.

In the past, we have remarked that the anaerobic organisms called $B$. corrodens appeared to be inappropriately placed in the genus Bacteroides, as they have a low DNA G+C content (28 to $30 \mathrm{~mol} \%$ ) and are oxidase positive (6). Most of the currently accepted Bacteroides species that have been examined have DNA G+C contents in the range of 40 to $46 \mathrm{~mol} \%$ and are oxidase negative. At this time we do not propose a new genus for these organisms, as there is need for more work to elucidate their relationship to other "unusual" anaerobic gram-negative rods. However, we regard these organisms as constituting a unique species, for which we propose the name Bacteroides ureolyticus (M.L. noun urea urea; Gr. adj. lyticus dissolving; M.L. adj. ureolyticus urea dissolving).

The strain designated by Henriksen (4) as the type strain of $B$. corrodens is a facultatively anaerobic strain that was transferred to a new genus, Eikenella (6). According to the rules of nomenclature, the name of a taxon is permanently attached to the type of the taxon. Thus, the name of the Eikenella species that contains the type strain of $B$. corrodens is $E$. corrodens, of which $B$. corrodens is an objective synonym. Because no two species names in the same genus may bear the same specific epithet, even if one of the names is regarded as a synonym, it is incorrect to refer to the anaerobic, urease-positive corroding rods as Bacteroides corrodens. Because we regard these rods as belonging to a new species of Bacteroides, a specific epithet different from "corrodens" and from any other specific epithet previously used in combination with the generic name Bacteroides had to be used for this species.

The type strain of $B$. ureolyticus is strain EDMH-1 (= NCTC 10941). Descriptions of the new species and of the type strain are given in Table 1.

Additional features of $B$. ureolyticus not included or not completely described in Table 1 are as follows.

Colonial morphology. Two colonial types may be produced by strains with long polar pili, and one or the other may predominate in a particular culture: (i) compact colonies, minute at $24 \mathrm{~h}$, enlarging to 0.5 to $1.0 \mathrm{~mm}$ at 48 to $72 \mathrm{~h}$; the colonies appear to be set in small pits in the agar; the centers of the colonies are often umbonate; and (ii) spreading or "swarming" colo- 
nies, in which a thin sheet of growth extends for a few millimeters from the center of the colony; sometimes a whole colony consists of a thin sheet of organisms, with no raised center; the zone of spreading growth may show concentric, slightly thickened rings, with thinner depressed growth between the rings. The whole sheet of growth appears to occupy a slight depression in the agar, so that the edge of the spreading growth is not detectably raised above the level of the surface of the medium.

Strains lacking polar pili do not form spreading colonies and produce only minimal pitting of the medium.

Cultural biochemical and metabolic characteristics. Growth is enhanced by $10 \%$ $\mathrm{CO}_{2}$ and by inclusion of $0.1 \%$ nitrate in solid media. Growth in liquid media is poor but is enhanced by the addition of fumarate and formate (12). Hemin and menadione produce slight enhancement of growth (7).

Oxidase positive by the tube test described above. The oxidase reaction is markedly inhibited by sodium azide.

Oxidase positive by the Kovacs method when tested with $1 \%$ tetramethylparaphenylenediamine but negative or doubtfully positive with $1 \%$ dimethylparaphenylenediamine monohydrochloride.

Visual spectroscopy of the organism shows absorption bands corresponding to reduced cytochrome $c(550 \mathrm{~nm})$ and a cytochrome $b$ component (555 to $560 \mathrm{~nm}$ ). No cytochrome $a$ band was detected.

Gelatin hydrolysis is demonstrable by the Frazier test (7) at 3 to 5 days. Liquefaction of $12 \%$ gelatin medium containing fumarate and formate (12) occurs by 5 days.

Weakly proteolytic strains are encountered.

No acid production is detected when cells are grown on hemin-supplemented phenol red medium (BBL) with taxo carbohydrate disks (BBL) or soft-agar deep stabs of phenol red medium with $1 \%$ substrate (substrates tested: glucose, adonitol, arabinose, dulcitol, galactose, inositol, lactose, maltose, mannose, mannitol, raffinose, salicin, sorbitol, sucrose, and trehalose). In this sense the organisms are "nonfermentative."

Cellular fatty acid profile. Organisms grown on modified Wahren and Holme medium
(9) contain octadecenoic acid as a major component ( $70 \pm 4 \%$ of $\mathrm{C}_{12}$ to $\mathrm{C}_{20}$ fatty acids). Hexadecanoic acid forms about $10 \%$ of the total; dodecanoic, tetradecanoic, and octadecanoic acids are present in low and variable concentrations.

Source. Isolated from face and limb lesions and from the genital tract of humans.

\section{REPRINT REQUESTS}

Address reprint requests to: Dr. Francis L. Jackson, Department of Medical Bacteriology, University of Alberta, Edmonton, Alberta, Canada.

\section{LTTERATURE CITED}

1. Brooks, G. F., J. M. O'Donoghue, J. P. Rissing, K. Soapes, and J. W. Smith. 1974. Eikenella corrodens, a recently recognized pathogen: infections in medicalsurgical patients and in association with methylphenidate abuse. Medicine 53:325-342.

2. Eiken, M. 1958. Studies on an anaerobic rod-shaped, gram negative microorganism: Bacteroides corrodens n. sp. Acta Pathol. Microbiol. Scand. 43:404-416.

3. Henrichsen, J. 1975. The occurrence of twitching motility among Gram-negative bacteria. Acta Pathol. Microbiol. Scand. Sect. B 83:171-178.

4. Henriksen, S. D. 1969. Designation of the type strain of Bacteroides corrodens Eiken 1958. Int. J. Syst. Bacteriol. 19:165-166.

5. Hill, L. R., J. J. S. Snell, and S. P. Lapage. 1970. Identification and characterization of Bacteroides corrodens. J. Med. Microbiol. 3:483-491.

6. Jackson, F. L., and Y. E. Goodman. 1972. Transfer of the facultatively anaerobic organism Bacteroides cor. rodens Eiken to a new genus, Eikenella. Int. J. Syst. Bacteriol. 22:73-77.

7. Jackson, F. L., Y. E. Goodman, F. R. Bel, P. C. Wong, and R. L. S. Whitehouse. 1971. Taxonomic status of facultative and strictly anaerobic "corroding bacilli" that have been classified as Bacteroides corrodens. J. Med. Microbiol. 4:171-184.

8. Khairat, O. 1967. Bacteroides corrodens isolated from bacteriaemias. J. Pathol. Bacteriol. 94:29-40.

9. Prefontaine, G., and F. L. Jackson. 1972. Cellular fatty acid profiles as an aid to the classification of "corroding bacilli" and certain other bacteria. Int. J. Syst. Bacteriol. 22:210-217.

10. Robinson, J. V. A., and A. L. James. 1973. Some serological studies on Bacteroides corrodens. J. Gen. Microbiol. 78:193-197.

11. Shobe, C. R. 1974. A microspectroscopic method for visualizing the cytochrome profiles of microorganisms. Can. J. Microbiol. 20:999-1005.

12. Smibert, R. M., and L. V. Holdeman. 1976. Clinical isolates of anaerobic Gram-negative rods with a formate-furmarate energy metabolism: Bacteroides corrodens, Vibrio succinogenes, and unidentified strains. J. Clin. Microbiol. 3:432-437. 